\title{
Strength assessment of the body of a weight checking wagon type 640-VPV
}

\author{
Yadgor Ruzmetov ${ }^{1}$, Nodir Adilov $^{1 *}$, and Shokhruk Sultonov ${ }^{2}$ \\ ${ }^{1}$ Tashkent State Transport University, 100167, Tashkent, Uzbekistan \\ ${ }^{2}$ Emperor Alexander I St. Petersburg State Transport University, 190031, Saint-Petersburg, Russia
}

\begin{abstract}
In the article, necessary to design and build new and modern weighing wagons to replace the outdated ones, but this will take some time. Thus, before the construction of new wagons and the optimal use of existing wagons, it is necessary to extend their service life. Extension of the service life of weighing wagons involves determining the current technical condition and residual resources of these wagons. For this purpose, a survey and analysis of the main bearing elements and structural parameters of the bodies of the weighing wagons were carried out.
\end{abstract}

\section{Introduction}

Railway transport, being the most important link in the transport system of the Republic of Uzbekistan, plays an important role in the development of the country's economy [1-2]. Improving the efficiency and competitiveness of the railway transport of the Republic of Uzbekistan in the implementation of the export and transit potential of the country as a transport bridge between Europe and Asia is directly related to the increase in the weight of trains using rolling stock with increased axle loads [3-6]. At the same time, scales are used to weigh railway transport in the country's railway network, which requires periodic checks [7-8]. Mechanized inspection of all types of wagon scales in the republic is provided by weighing wagons of the 640-VPV type [9-10].

The weighing wagon checks the wagon scales with the highest weighing limit, thereby ensuring the accuracy and accuracy of the readings of the weighing instruments [11].

On the railways of the Republic of Uzbekistan, more than ten weight-checking wagons of the 640-VPV type, produced in 1965-1966, are used, which are outdated [12]. At present, it is necessary to develop and build new and modern two-axle weighing wagons of the A-300 type, but this will take some time. Thus, before the construction of new wagons and the optimal use of existing wagons, it is necessary to extend their service life. Extension of the service life of the weighing wagons involves determining the current technical condition and residual resources of these wagons.

*Corresponding author: adilovnodir1991@gmail.com 

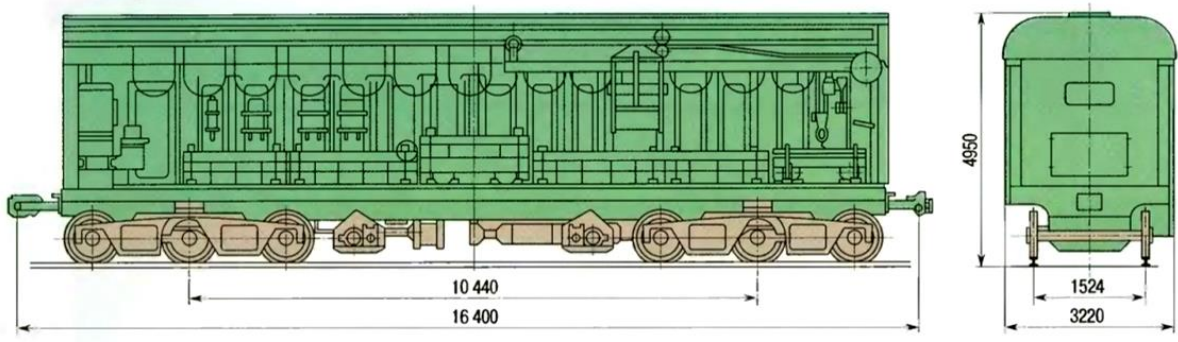

Fig. 1. The 640-VPV type weight-checking wagon

For this purpose, a survey and analysis of the main load-bearing elements of the bodies of weighing wagons were carried out to determine the current technical condition and residual resources of these wagons and the development of technical documentation to extend their service life.

The weight checking wagon of the 640-VPV type (Fig. 1) is designed based on a sixaxle gondola wagon with a carrying capacity of 93-95 tons and has standard shock and traction devices, and a brake system, which allows it to be included in the train at set speeds up to $120 \mathrm{~km} / \mathrm{h}[13]$.

The whole-metal body of the weighing wagon is a welded structure of a frame, two side walls, two end walls and a roof. The wagon contains a boom telpher, an electric power cabinet, a diesel power plant, control equipment, a workbench for locksmith's work, a cabinet for clothes and tools. On the floor of the weighing wagon, two self-propelled weighing bogies and 36 (38) model weights of accuracy class M1 weighing $2000 \mathrm{~kg}$ [14] are laid. Technical characteristics and main parameters of the weighing wagon are shown in Table 1.

Table 1. Technical characteristics of the weighing wagon

\begin{tabular}{|c|l|c|}
\hline № & Technical characteristics & Value \\
\hline 1 & Total weight of model weights and weighing trolleys, $\mathrm{t}$ & 80 \\
\hline 2 & Number of exemplary weights of the 4th grade, pcs. & 38 \\
\hline 3 & Mass of an exemplary weight of the 4th category, $\mathrm{kg}$ & $2000 \pm 0,2$ \\
\hline 4 & Number of weight verification trolleys, pcs. & 2 \\
\hline 5 & Weight of the weighing trolley, $\mathrm{kg}$ & $2000 \pm 0,2$ \\
\hline 6 & Maximum load on the weighing trolley, $\mathrm{t}$ & 40 \\
\hline 7 & The base of the weighing trolley, mm & 980 \\
\hline 8 & Travel speed of the weighing wagon from its own drive, $\mathrm{m} / \mathrm{min}$ & 23 \\
\hline 9 & Boom extension speed of telpher, $\mathrm{m} / \mathrm{min}$ & 30 \\
\hline 10 & Speed of movement of the weighing trolley, m / min & 24 \\
\hline 11 & The most possible removal of the weighing trolley from the wagon, $\mathrm{m}$ & 30 \\
\hline 12 & Weight of a wagon with exemplary equipment, $\mathrm{t}$ & 127 \\
\hline 13 & Wagon width, mm & 3220 \\
\hline 14 & Carriage base, $\mathrm{mm}$ & 10440 \\
\hline 15 & Wagon length along the coupling axes of the automatic coupler, mm & 16400 \\
\hline 16 & The construction of the wagon is designed for speed, $\mathrm{km} / \mathrm{h}$ & 120 \\
\hline
\end{tabular}

The frame of the weighing wagon is made of 09G2 low-alloy steel and consists of beams: center beams, two buffer, two pivot and five transverse beams. The main beam is made of two Z-shaped beams, to which an I-beam with a section of $190 \times 75 \times 7 \mathrm{~mm}$ is welded along its entire length. 
At the ends of the backbone girder, rosettes are attached, combined into one casting with the front stop angles. At a distance of $625 \mathrm{~mm}$ from them, the rear stop brackets of the automatic coupler are attached also combined into a common casting.

The pivot girder has an $8 \mathrm{~mm}$ thick top sheet fitted with a corrugation along the girder. The vertical sheets of the pivot girder are $6 \mathrm{~mm}$ thick. Center plates are fixed on the bottom sheet of $10 \mathrm{~mm}$ thick, with $22 \mathrm{~mm}$ diameter bolts.

The intermediate transverse beam has an upper chord $180 \mathrm{~mm}$ wide and $8 \mathrm{~mm}$ thick, equipped with a corrugation, and vertical sheets $6 \mathrm{~mm}$ thick. The lower belt consists of two corners with a cross-section of $50 \times 50 \times 5 \mathrm{~mm}$, connected in the middle by a strip.

The side wall of the body consists of two pivots and five intermediate struts, bottom and top straps and sheets of metal sheathing welded to the frame. The upper trim of the side wall is made of a channel with a section of $140 \times 60 \times 8 \mathrm{~mm}$ and reinforced with ribs, and the lower one is made of a corner with a section of $150 \times 100 \times 10 \mathrm{~mm}$. To increase the rigidity of the skin, a trough-like shape was formed by stamping, and the thickness of the skin was $4 \mathrm{~mm}$.

On one of the end walls of the wagon, there is a window and a hatch covered with shutters for servicing the diesel engine. The other end opening is closed across the entire width by double-leaf doors designed for unloading and loading weights and carts.

The wagon roof consists of nine arcs of an I-profile with a section of $285 \times 80 \times 10 \mathrm{~mm}$, which are reinforced with each other by straps of an angle profile. The roof frame is covered with $3 \mathrm{~mm}$ metal sheathing. To hold the boom of the electric hoist, a beam is fixed on the roof, which is made of two I-beams. A hoist with a lifting capacity of two tons moves along the I-beam of the boom.

\section{Methods}

To determine the technical condition, five wagons were selected from the weighing wagons available on the territory of the Republic of Uzbekistan. At the first stage of analysing these wagons, several malfunctions were identified that affect their service life. The depth gauge measured the thickness of wear of the metal structure elements of the weighing wagons bodies. Based on the results of measurements of wear thicknesses $h^{i}$, the value of the average wear thickness $h_{c p}^{i}$ was calculated, taking into account the tolerance $" \delta=0.2 \mathrm{~mm} "$ for cleaning, which is determined by the formula:

$$
h_{c p}^{i}=\frac{1}{n} \sum_{i}^{n} h^{i}-0.2
$$

Where $\mathrm{n}$ is the number of measurements.

From the data obtained from the five investigated weighing wagons, the average value of sheet wear was determined for the elements of metal structures of the weighing wagon using the formula:

$$
h_{c p}=\frac{1}{n} \sum_{i}^{n} h_{c p}^{i}
$$

The results of the average values of the wear values for the beams of the weighing wagon are presented in Table 2 . 
Table 2. Results of the average values of wear values for the elements of the weighing wagon

\begin{tabular}{|c|c|c|c|c|}
\hline Model & Spinal beam & Pivot beam & End beam & Longitudinal beam \\
\hline 640-VPV-271 & 0.77 & 0.43 & 0.94 & 0.79 \\
\hline 640- VPV-267 & 0.74 & 0.46 & 0.86 & 0.83 \\
\hline 640- VPV-263 & 0.77 & 0.44 & 0.92 & 0.74 \\
\hline 640- VPV-277 & 0.67 & 0.47 & 0.93 & 0.76 \\
\hline 640- VPV-285 & 0.77 & 0.43 & 0.92 & 0.75 \\
\hline$h_{c p}$ & 0.74 & 0.45 & 0.91 & 0.77 \\
\hline
\end{tabular}

At the second stage, the results obtained for the average values of wear thickness for the elements of the weighing wagon were used in the strength calculations of the metal structure of the weighing wagon.

Thus, when carrying out strength calculations of the metal structure of a six-axle weighing wagon of the 640-VPV type, the wall thickness was taken, taking into account its decrease by the value of the average wear value, i.e. average wear values were subtracted from the size of the thickness of the element sheets.

The strength of the body of the weighing wagon following the requirements of [15] was evaluated under two design modes:

a) according to the first design mode, a relatively rare combination of extreme loads was considered. The main requirement when calculating the strength according to this mode is to prevent the appearance of permanent deformations (damages) in the unit or part;

b) according to the third design mode, a relatively frequent possible combination of moderate loads, typical for the normal operation of a wagon in a moving train, was considered. The main requirement in the calculation for this mode is to prevent fatigue failure of a unit or part.

Following the requirement [15] for the applied steels, the elastic modulus was taken equal to $2.1 \cdot 10^{5} \mathrm{MPa}$, the Poisson's ratio was taken equal to 0.3 .

\section{Results and Discussion}

The calculation was performed by the finite element method using the Ansys Workbench finite element package. For the calculation, a volumetric finite element model of the body of a weighing wagon was used. Body elements were imitated by volumetric linear finite elements with three degrees of freedom at each node: three displacements [1617]. The carriage bogies were imitated by elements of the lumped mass type. Elements of the mass type were connected to the wagon frame using absolutely rigid connections. The design model of the assembly includes 180,720 elements and 57,714 assemblies. The general view and view of the finite element model of the wagon body are shown in Figures 2-3.

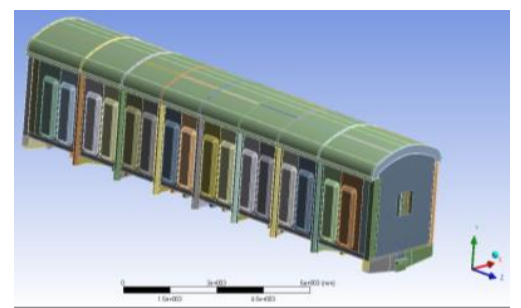

Fig. 2. General view of the design model of the body of the weighing wagon

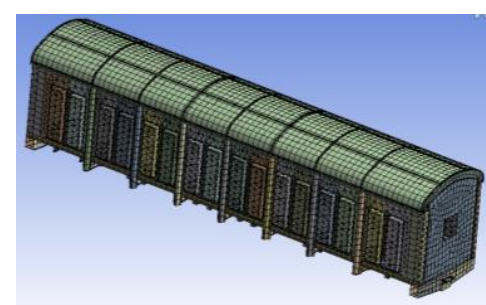

Fig. 3. General view of the finite element model of the wagon body 
Kinematic and force boundary conditions for different design modes are shown in Figure 4.

The body of the weighing wagon was calculated for strength in the first (impact, jerk, compression and tension) and third (impact, jerk, compression and tension) design modes and the combination of loads acting on the body of the weighing wagon in the first and third design modes, was determined following requirement [15].

The longitudinal force of inertia of the body and bogies of the weighing wagon was determined by multiplying the mass of the body of the weighing wagon by the normalized value of the longitudinal acceleration[18]. The longitudinal force of inertia of the load $N_{u}$ was determined by the formula

$$
N_{u}=N \frac{m_{g r}}{m_{v a g}}
$$

Where the $N$ is external longitudinal impact force.

Substituting the data into formula (1), we obtained that the inertia force of the load was for the first mode at impact $N_{u}=2.2 \mathrm{MN}$, with a jerk $N_{u}=1.6 \mathrm{MN}$ (for the third mode, $N_{u}=$ $0.63 \mathrm{MN})$

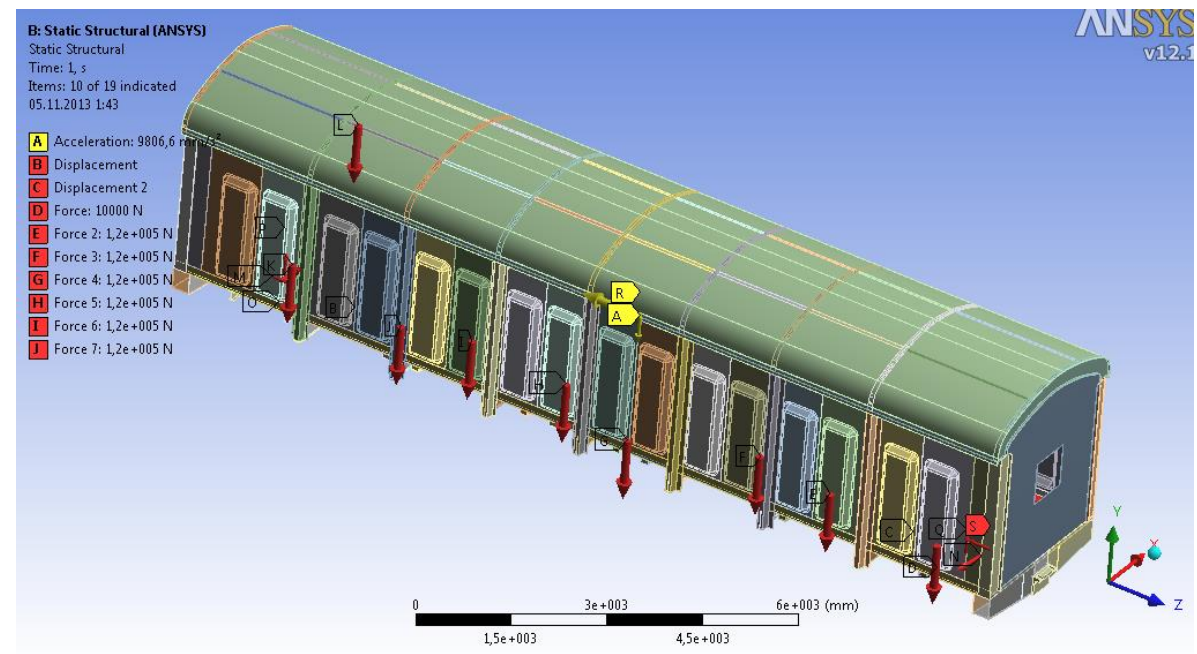

Fig. 4. Kinematic and force boundary conditions during compression (tension) of a wagon by quasistatic and dynamic forces (according to I and III design modes)

The vertical force in the case of off-center interaction of [19] automatic couplers $P$ was determined by the formula

$$
P=N \frac{e}{b}
$$

Where $e$ is the differencing the levels of the automatic coupler axles;

$\mathrm{b}$ is length of a rigid rod formed by two coupled automatic couplings.

Substituting the data into formula (2), we obtained that the force at off-center interaction of automatic couplers was for the first mode at impact $\mathrm{P}=175 \mathrm{kN}$, at jerk $\mathrm{P}=138 \mathrm{kN}$ (at compression $\mathrm{P}=125 \mathrm{kN}$, at tension $\mathrm{P}=110 \mathrm{kN}$ ), for the third mode $\mathrm{P}=25 \mathrm{kN}$ in impact and compression, $\mathrm{P}=27.6 \mathrm{kN}$ in jerk and tension). 
The transverse forces of interaction between the wagons in [20-21] the curves Pn were determined by the formulas:

- when compressed

$$
P_{n}=N\left[\frac{\delta \cdot L}{l^{2}}\left(1+\frac{L}{a}\right)+\frac{L_{C}}{R}\right] \frac{l}{L},
$$

- under tension

$$
P_{n}=N \frac{L_{c}}{R}
$$

where $21,2 \mathrm{~L}, 2 \mathrm{Lc}$ - respectively the base of the wagon, the distance between the stop plates of the automatic couplers and the length of the wagon along the coupling axes of the couplers;

$a$ is calculated length of the coupler body;

$\mathrm{R}$ is the radius of the curve;

$\delta$ is possible lateral displacement of the pivot section of the wagon body due to wheelset clearances in the rail track, clearances in axle-box guides, center plates and elastic deformations of springs.

Substituting the data into formulas (3) and (4), we obtained that the transverse forces of [22] interaction between the wagons in the curves are for the first regime under compression $P_{n}=214.1 \mathrm{kN}$, with tension $P_{n}=65.6 \mathrm{kN}$. 589

The coefficient of vertical dynamics $K_{d v}$ was determined by the formula:

$$
K_{d v}=\frac{K_{d v}^{c p}}{\beta} \cdot \sqrt{\frac{4}{\pi} \cdot \ln \frac{1}{1-P\left(\mathrm{~K}_{d v}\right)}}
$$

Where $K_{d v}^{c p}$ is the average probable value of the coefficient of vertical dynamics, determined by the formula (6);

$\beta$ is distribution parameter; $P\left(K_{d v}\right)$ is confidence probability with which the coefficient of vertical dynamics that is determined, $P\left(K_{d v}\right)=0.97$.

The average probable value $K_{d v}^{c p}$ was determined by the formula:

$$
K_{d v}^{c p}=a+3.6 \cdot 10^{-4} \cdot \operatorname{s} \cdot \frac{v-15}{f_{c m}}
$$

where: $\boldsymbol{A}$ is coefficient for body elements; $\boldsymbol{B}$ is coefficient taking into account the influence of the number of axles $\mathrm{n}$ in the bogie under one end of the carriage; $f_{\mathrm{cm}}$ is spring suspension static deflection, $\mathrm{m}$.

Substituting data into formula (5), we got $K_{d v}=0.35$. 


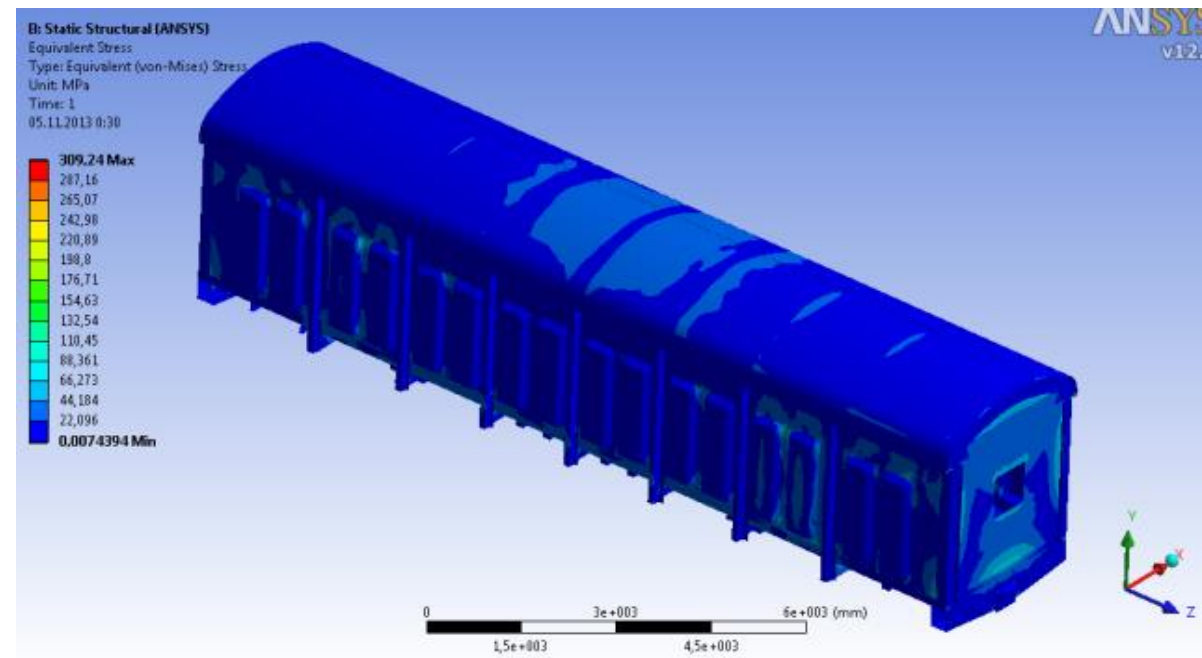

Fig. 5. Fields of distribution of equivalent stresses in the elements of the weighing wagon (I mode, dynamics), MPa (general view)

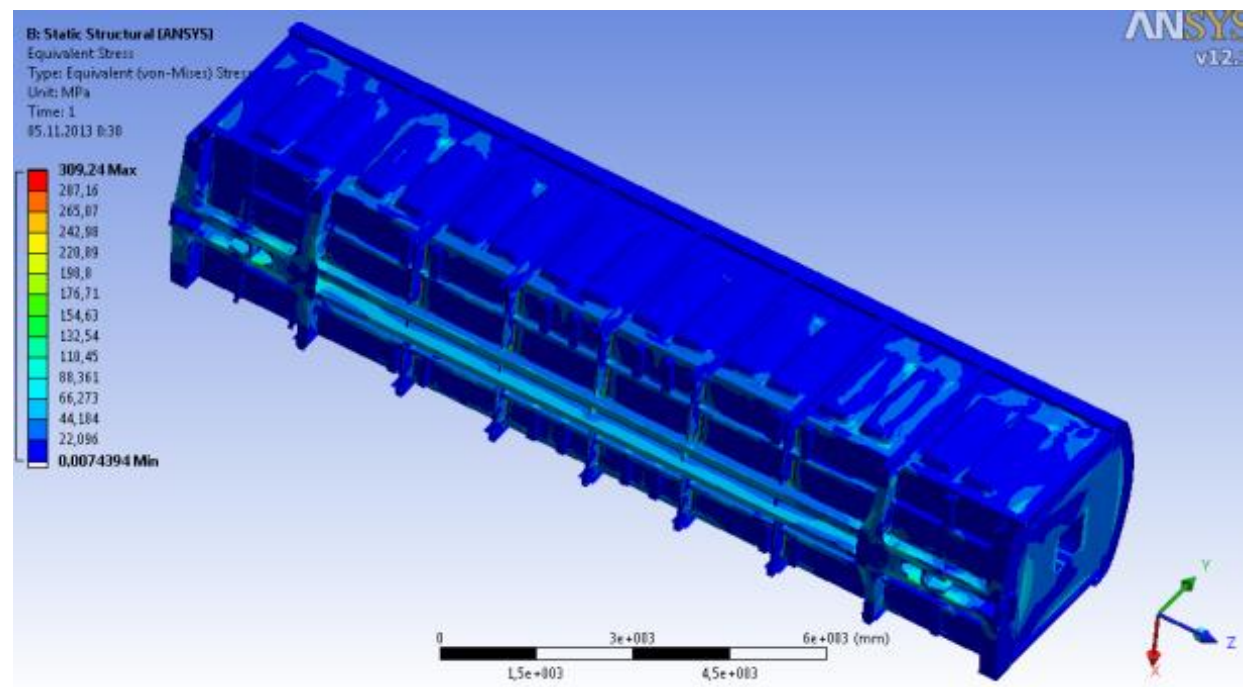

Fig. 6. Fields of distribution of equivalent stresses in the elements of the weighing wagon (I mode, dynamics), MPa (bottom view)

The strength assessment following the requirement [15] was carried out by equivalent stresses calculated according to the Mises theory. The distribution fields of the equivalent maximum stresses of the body elements for the considered design modes are shown in Figure 5-6.

\section{Conclusions}

As a result of a preliminary assessment of the strength of the body of the weighing wagon according to [15], it was found that the strength, taking into account the wear of the body elements, meets all the established requirements. Wherein the following results were obtained: 
1. At the I design mode (compression, tension, statics, dynamics), the maximum stresses in the body elements are 36-62 $\mathrm{MPa}$ in the side walls, 255-305 $\mathrm{MPa}$ in the center beam elements;

2. At the III design mode (compression, tension, statics, dynamics), the maximum stresses in the body elements are 30-56 MPa in the side walls, 142-185 MPa in the center beam elements.

\section{References}

1. Rasulov M.X. Problems of increasing the competitiveness of domestic railway corridors, Scientific works of the Republican scientific and technical conference with the participation of foreign scientists, Resource-saving technologies in railway transport, pp. 14-17, Tashkent, (2013)

2. Rahimov R.V. Ways to increase the transit potential of the Republic of Uzbekistan, Vestnik TashIRI, 2017, № 1, pp. 120-127.

3. Rahimov R.V. Analysis of the state and prospects of the development of the freight wagon fleet of the Republic of Uzbekistan, Non-Ferrous Metals, № 1, 44, pp. 7-11, (2018)

4. Ruzmetov Y.O. Perspectives of wagon development in the Republic of Uzbekistan, Collection of scientific papers of the VIII All-Russian conference "Problems and prospects for the development of carriage building" Bryansk, BGTU, pp. $147-150$. (2019)

5. Rahimov R.V. Choice of directions for the development of the wagon fleet of railways of Uzbekistan, Transport of the Russian Federation, № 1, pp. 71-74, (2018)

6. Rahimov R.V. State and prospects of development of the wagon fleet of the railways of Uzbekistan, Materials of the XIII International Conference "Rolling stock of the XXI century: ideas, requirements, projects", SPB. PGUPS, pp. $124-128$, (2018)

7. Ikonnikov E.A. Means for measuring mass and weighing means used in railway transport, M.: Marshrut, p. 40, (2003)

8. GOST 30414-96. Scales for weighing vehicles in motion. General technical requirements. Minsk, PPK Publishing house of standards, p. 8, (1997)

9. Rahimov R.V. Analysis of the technical condition of the main load-bearing elements and structural parameters of the bodies of weighing wagons of the 640-VPV type, Scientific works of the Republican scientific and technical conference "Resourcesaving technologies in railway transport", pp. 49-52. Tashkent, (2013)

10. Rahimov R.V. Theoretical studies of the metal structure of the 640-VPV type weighing wagon, Vestnik TashIRI. -№ 3, pp. 52-59, (2013)

11. Care and maintenance manual. 640-VPV type weighing wagon, p. 38

12. Rahimov R.V. Technical analysis and strength researches of bearing elements of weight calibration wagon bodies Proceedings VIII International Scientific Conference "Transport Problems 2016", Katowice: Silesian University of Technology Faculty of Transport, pp. 487-495, (2016)

13. Rahimov R.V. Weighing wagon: design, inspection, calculation and service life extension, Monograpfy, p 136, Tashkent, Uzbekistan, (2017)

14. GOST 7328-2001. Giri. General specifications. - Minsk.: PPK Publishing house of standards, p.11, 2012

15. Standards for the calculation and design of new and modernized wagons of the railways of the Ministry of Railways with a gauge of $1520 \mathrm{~mm}$ (non-self-propelled). M.: GosNIIV-VNIIJT, p. 317, (1996) 
16. Zaynitdinov O.I., Rahimov R.V., Waail M.L., Ruzmetov Y.O. Development of new polymer composite materials for the flooring of rail carriage, International Journal of Engineering and Technology, 9 (2), pp. 378-381, (2020)

17. Turanov $\mathrm{Kh}$ and Ruzmetov $\mathrm{Y}$. The problem of fastening cargo on railway rolling stock, E3S Web of Conferences 157, 01008 (2020)

18. Ruzmetov Y., Molchanova O., and Shihnazarov J. Calculation of solid-state cargo fastener under the influence of longitudinal forces, E3S Web of Conferences 157, 01016 (2020)

19. Turanov Kh and Ruzmetov Y. On the shift of cargo on a railway platform under the influence of transverse forces, E3S Web of Conferences 157, 01012 (2020)

20. Turanov Kh., Ruzmetov Y., and Shikhnazarov J. Incorrectness of the method of calculating cargo fastening on railway platforms, E3S Web of Conferences 164, 03040 (2020)

21. K. Turanov, A. Gordienko, S. Saidivaliev, S. Djabborov. Designing the height of the first profile of the marshalling hump, E3S Web of Conferences, 164, 03038 (2020)

22. K.T. Turanov, S.U. Saidivaliev, D.I. Ilesaliev. Determining the kinematic parameters of railcar motion in hump yard retarder positions, Structural integrity and life, 20, № 2, pp. 143-147, (2020) 